\title{
HYBRID JOINING OF STEEL AND PLASTIC MATERIALS BY LASER BEAM
}

\author{
Andor Bauernhuber, Tamás Markovits \\ Dept of Automobiles and Vehicle Manufacturing, \\ Budapest University of Technology and Economics, Hungary
}

Submitted 31 January 2012; accepted 20 August 2012; first published online 22 May 2013

\begin{abstract}
Hybrid joining of metals and plastics in order to produce lightweight parts is of growing interest in the manufacturing processes of vehicles, electrical devices and biomedical applications. In this study, the joining of PMMA plastic (poly methyl metacrylate) and unalloyed steel were investigated by the authors. The authors successfully joined PMMA and steel by means of Nd:YAG laser and carried out tensile tests to measure the joining strength. Experimental results showed that the joint strength is influenced by the heating time, the penetration depth of the steel workpieces in the plastic, by the surface roughness of steel and by the time elapsed between bonding and tearing of the samples.
\end{abstract}

Keywords: laser, hybrid joining, steel, plastic, experiment.

Reference to this paper should be made as follows: Bauernhuber, A.; Markovits, T. 2014. Hybrid joining of steel and plastic materials by laser beam, Transport 29(2): 217-222. http://dx.doi.org/10.3846/16484142.2013.785445

\section{Introduction}

Nowadays, metals and plastics can be found in the majority of our equipments. Accordingly, the two materials often have to be combined, they have to be joined. The joining of metal and plastic parts is frequently needed for example in case of vehicles, at the front-end carriers of the car body (Wang et al. 2010; Amanat et al. 2010). In our vehicles there are electrical instruments with insulations and housings, which also have to be joined. In case of vehicles, the increasing use of plastics is generated by weight reduction ambitions (Farazila et al. 2011). Hence, we need new technologies to permit the joining of metals and plastics in the vehicle industry. The joining technologies applied to combine metals and plastics can be clustered in two groups: technologies without heat effect and technologies using heat input. Technologies without heat input are applying mechanical fastenings such as screws and rivets or adhesives. However, mechanical joining can be disadvantageous because of:

- the caused high internal stress;

- the bad esthetical appearance;

- the restricted designing;

- the difficult automation possibility.

Disadvantages of the adhesives are their harmful volatile compounds and long bonding time (Fortunato et al. 2010). Lately, heat input application in forms such as laser technologies have been developing very fast; and they are also used to bond metals and plastics. Furthermore lasers are used in LTCC technology as well (Horváth, Harsányi 2010), which is crucial in sensor technology and commonly used in car industry. In this case, the laser beam is used directly to bond the two materials, without any additive materials (Katayama, Kawahito 2008; Wahba et al. 2011).

Laser is an electromagnetic radiation, created in the resonator and led to the workplace by different optical elements. A specific laser light can be reflected, absorbed or transmitted depending on the material used. The features of the beam are the small divergence and the big coherence (the waves of the emitted photons are always in the same phase). Bringing the laser beam into focus, a very high energy density is available, which allows welding or cutting metals and plastics by a high speed. In case of metal-metal and plastic-plastic joining the process is used in the industry, but in case of hybrid metal-plastic joining the research is still in an initial stage (Somogyi, Takács 2009; Devrient et al. 2011; Roesner et al. 2011).

In the experiments a laser beam was used as a heat source to create a joint between steel and plastic by a pulsed mode Nd:YAG laser source. The aim was to create hybrid joints and determine the factors that influence the process and the strength of the joints. Investigations had been carried out in order to examine the effect of the heating time, the penetration depth of the steel pin into the plastic plate, the surface condition of steel (average surface roughness) and the time elapsed between joining and tearing. Based on the results, the strength values were compared with an alternative technology (gluing). 


\section{Experiments}

Steel samples with plastic sheets were bonded. The steel material was S235JRC structural steel with $235 \mathrm{MPa}$ yield strength, the plastic material was polymethyl metacrylate (PMMA Acriplex PMMA-XT). This plastic was chosen because of its good strength results during the preliminary experiments and because of its transparency: the structural changes in the plastic and the connection area can be observed easily. The laser beam source was a LASAG SLS 200 type, pulse mode Nd:YAG laser with maximal pulse power of $P_{\max }=5.5 \mathrm{~kW}$ and with an average power of $P_{a}=220 \mathrm{~W}$. The power distribution of the laser beam was Gaussian $\left(\mathrm{TEM}_{0,0}\right)$. The applied laser settings were the following: $f=100 \mathrm{~Hz}$, $t_{p}=0.5 \mathrm{~ms}, U=375 \mathrm{~V}$, where $\mathrm{f}$ is the pulse frequency, $t_{p}$ is the pulse duration in time, $U$ is the exciting voltage. The diameter of the laser spot was $5 \mathrm{~mm}$, as well as the face surface of the steel workpiece, and the spot was positioned concentrically with the steel sample. The laser head did not move during the process. During the experiments, argon shielding gas was used, the amount of argon was $4.75 \mathrm{l} / \mathrm{min}$.

The experimental setup can be seen in Figs 1 and 2 . The geometry of the steel workpiece can be seen, the size of the plastic sheet was $15 \times 15 \times 2 \mathrm{~mm}$.

The steel part and the sheet were put into a special clamping unit, the sheet placed on the top of the steel part. During the laser joining process, the laser beam is transmitted through the plastic material and the light is absorbed on the steel surface. So, the steel is heated directly and then, it heats the plastic, so the plastic becomes softer and finally melts or decomposes, according to the amount of the inputted heat. During this process the steel part is pushed into the soft plastic by means of a spring force which was $3.5 \mathrm{~N}$. By the end of the process, the steel pin gets penetrated into the sheet. The pin is surrounded by a burr and the joint is created.

To investigate the bonding force, the 3 workpieces were torn in every setup, the force was measured with a force tester PCE FG 500. The workpieces were torn after two days, except when the effect of the waiting time was investigated. The tearing speed was $25 \mathrm{~mm} / \mathrm{min}$. The tensile strength of the applied PMMA was $83 \mathrm{MPa}$. The glass temperature is $105^{\circ} \mathrm{C}$, the melting point is $140{ }^{\circ} \mathrm{C}$, the degradation temperature is $200{ }^{\circ} \mathrm{C}$. Due to the not obvious contact surfaces (top and side surfaces) of the joint just the maximal tearing force is given in the diagrams.

First, the effect of heating time was investigated $\left(t_{h}\right)$ in connection with the penetration depth, and the penetration depth in relation to the tearing force and the heating time in relation to the tearing force.

The authors have determined the time interval in which the joint could be created. The shortest time when a joint was created was $3 \mathrm{~s}$. A shorter heating time did not enable the development of a joint between the pieces. The longest time was $7 \mathrm{~s}$, because after this time, the plastic became very soft, the decomposition degree was higher and the steel pin could easily go through the

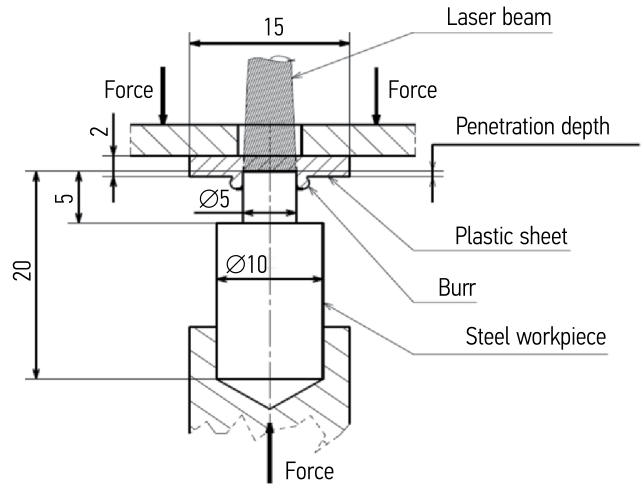

Fig. 1. Schematic view of the experimental setup (source: own drawing)

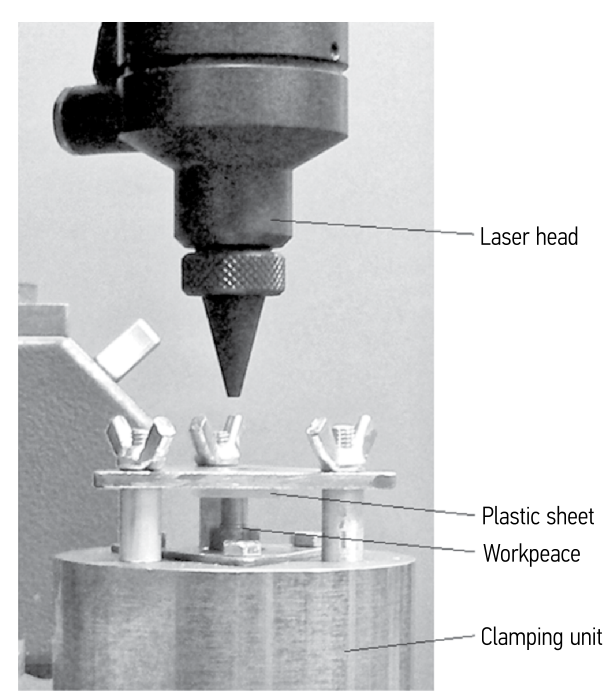

Fig. 2. Photo of experimental setup (source: own edition)

whole thickness of the plastic sheet, so, that the measured indentation became bigger than $2 \mathrm{~mm}$. Therefore the presented heating time values were $3,4,5,6$ and $7 \mathrm{~s}$. The average surface roughness $\left(R_{a}\right)$ of the workpieces ranged from 1.2 to $2.5 \mu \mathrm{m}$.

Before the experiment the length and the surface roughness on the lateral surface of the pins were measured and they were cleaned with acetone. After that, the steel and plastic parts were put into the clamping unit and the bond was created. At the end, the joint height of the steel and plastic parts was measured to calculate the penetration depth into the plastic. The surface roughness of the workpieces was about $1 \mu \mathrm{m}$.

The effect of the surface roughness to the tear force was also examined: steel workpieces with different surface roughness, from $R_{a}=0.5 \mu \mathrm{m}$ to $R_{a}=10 \mu \mathrm{m}$ were developed. The pieces were made with turning and the surface roughness was controlled by changing the feed rate and the rotational speed while the cutting depth and the tool geometry were unchanged. The roughness values were measured by a Mitutoyo Surftest 301 surface roughness tester. In these cases the heating time was $6 \mathrm{~s}$.

The effect of the elapsed time between the creation of the joint and tearing $\left(t_{t}\right)$ was investigated, as the plas- 
tic material is influenced by a shrinkage effect after the heating that causes an increase in strength. Therefore the samples were torn $5 \mathrm{~min}, 1 \mathrm{~h}, 12 \mathrm{~h}, 1,2,3,4$, and 5 days after the joining process. In this case the average surface roughness of the workpieces ranged from 0.5 to $1.5 \mu \mathrm{m}$ and the heating time was $6 \mathrm{~s}$.

At last, some experiments were carried out with adhesive material (glue) to compare our results with an easy alternative technology. The instant glue was Pelican Daniels power fix CA.

\section{Results}

Fig. 3 shows a typical laser produced hybrid metal-polymer joint. It can be seen that the metal pin penetrated into the plastic sheet. The laser heats up the upper surface of the metal pin and the pin melts the plastic which flows back next to the metal surface creating a burr at the bottom of the plastic sheet.

The created joint before and after the tearing can be seen in Fig. 4. The changes of tearing force as a function of time, in case of two typical characteristic tearing forces are shown in Fig. 5. The samples were heated for $3,4,5$ and $6 \mathrm{~s}$. In each case the force increases until the maximal force, when it falls fast as the tear has occurred. The maximum force increases with the heating time from $180 \mathrm{~N}$ to $220 \mathrm{~N}$. By samples 1 and 2, the force falls to zero immediately, by samples 3 and 4 , and after the fall the force decreases slowly until the plastic sheet is separated from the steel.

At heating times of 3 and $4 \mathrm{~s}$, the indentation is low (around $0.1 \mathrm{~mm}$ ) and only the face is playing a role in the bond. Hence, when the face is torn the force falls fast to zero. In case of 5 and $6 \mathrm{~s}$ of heating time, the lateral surface of the pin also takes part in the bond formation

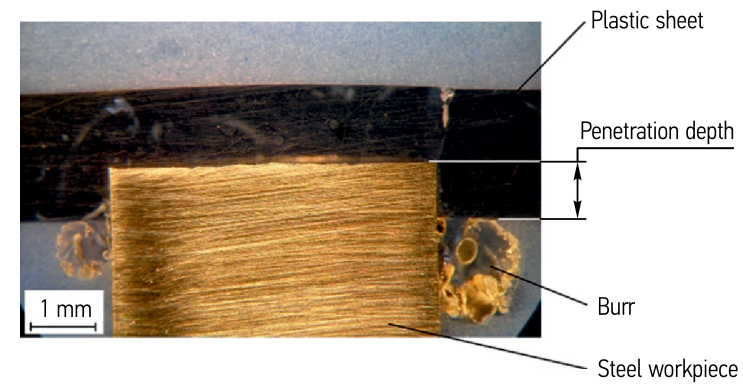

Fig. 3. Typical metal -polymer hybrid joint (source: own photo)
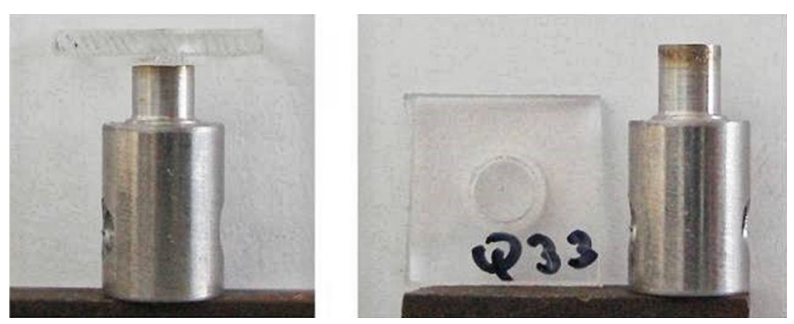

Fig. 4. Joint before and after tearing test (source: own photos) and after the first fall the surfaces of the plastic and the pin are still connected, therefore it takes some more seconds to completely separate the parts.

The penetration depth is plotted in Fig. 6 against the heating time. The average and the standard deviation were marked on the diagram. It can be seen that the penetration depth increases in a growing rate with the heating time, the deviation is small.

It can be seen that the indentation grows if the heating time is longer. This is a simple process: if the plastic is heated more and more by the steel surface, it starts to soften. Accordingly, the longer the heating, the easier and deeper is the steel pin penetrating into the plastic due to the applied spring force.

The maximal tearing force can be seen in Fig. 7 as a function of the penetration depth. It can be seen that the maximal tearing force increases with the higher

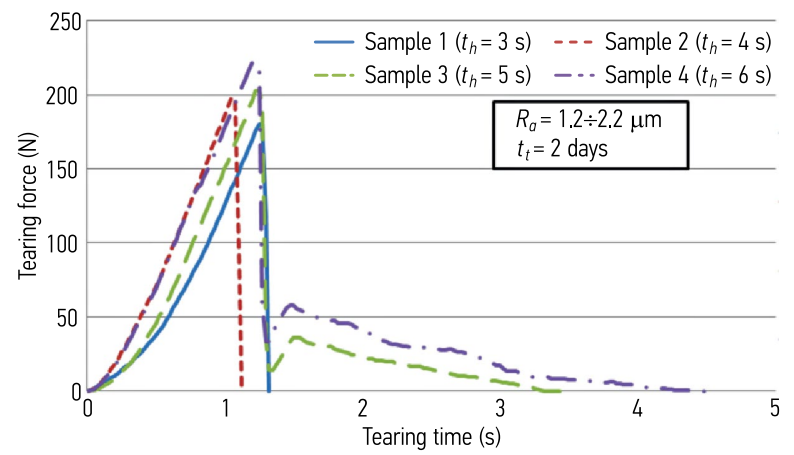

Fig. 5. Characteristic tearing forces in the function of time (source: own measurement)

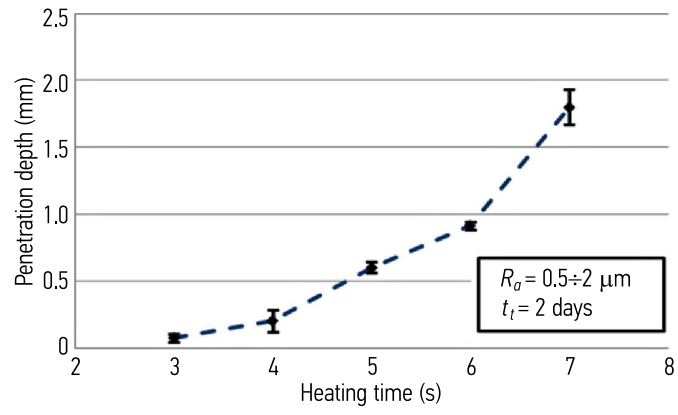

Fig. 6. Effect of heating time on penetration depth (source: own measurement)

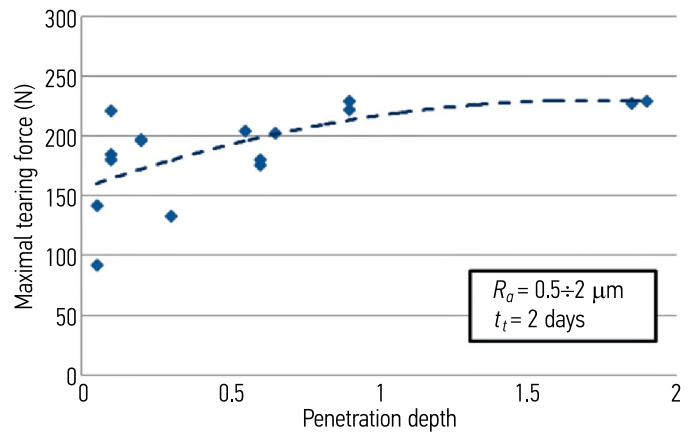

Fig. 7. Influence of penetration depth on maximal tearing force (source: own measurement) 
penetration depth and at lower penetration depth the deviation of the force values is higher. This higher deviation should be due to the fact that the lower penetration means that just the face side surface of the pin participates in forming the bond. This connection is not so robust as that with the lateral surface. The deeper the penetration depth the lower is the deviation.

The slowing rate can be explained with another parallel phenomenon: the formation of bubbles in the plastic material. These bubbles are formed close to the upper steel surface. The size and the amount of the bubbles increase if the heating time is longer. This causes a decrease in the tear force because the material weakens at the contact surface. The bubble formation can be seen in Fig. 8 in case of different heating times. The more the heating time (penetration depth) the more parts of the plastic are softened and the bigger the size of the created bubbles.

The temperature of the PMMA degradation is $200^{\circ} \mathrm{C}$. To measure the temperature is difficult because the joint geometry does not allow suitable access with a thermocouple or thermovision. The highest temperature have to be on the center of the top surface of the steel pin because of the Gaussian $\left(\mathrm{TEM}_{0,0}\right)$ distribution of the laser beam. In order to estimate the temperature, the colors of the top pin surface were compared with the tempering color scale by own experiments. The color of the pins show that the temperature was between $200 \div 250^{\circ} \mathrm{C}$ in case of longer heating time which is higher than the degradation temperature. Some other authors, for example - Katayama and Kawahito (2008) - reported that the bubble formation occurred during laser hybrid joining due to the decomposition of polymer in case of LAMP technology.

In Fig. 9 the maximal tearing force can be seen as a function of the heating time. A similar tendency can be seen in Fig. 7. The increasing force can be explained as an effect of deeper penetration. The growing penetration is caused by longer heating times and by the higher temperatures. The deviation is higher in the shorter heating time region as it has been analyzed earlier. The penetration depth and the bubble formation have contrary effects on the tearing force. The force increases slower than the penetration as a function of heating time. The slower increasing tendency is caused by the formed bubbles which produce discontinuities in the polymer material.

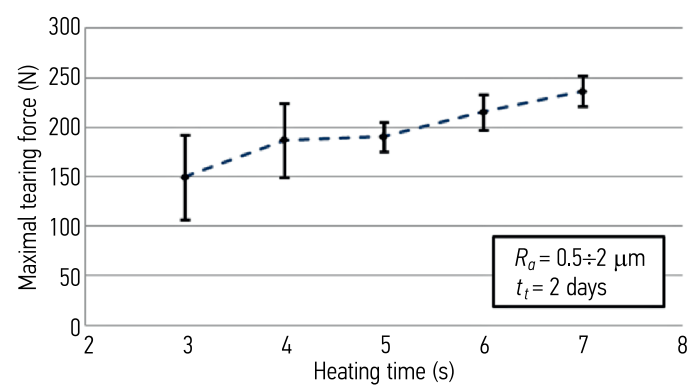

Fig. 9. Effect of heating time on maximal tear force (source: own measurement)

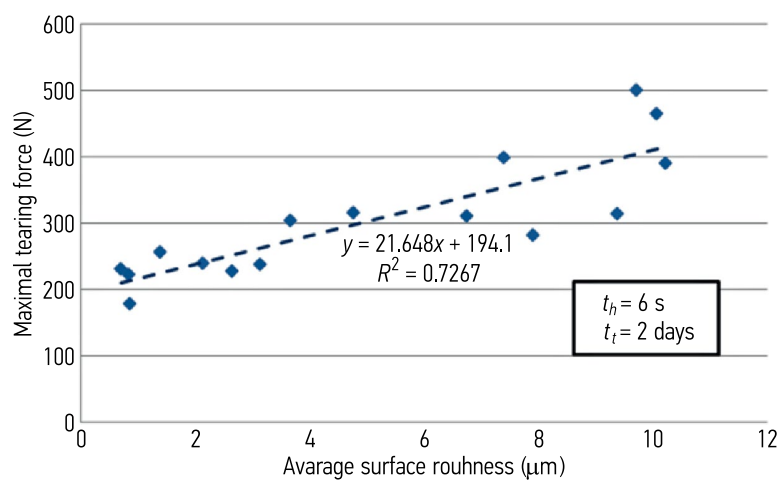

Fig. 10. Effect of surface roughness on maximal tearing force (source: own measurement)

The effect of surface roughness to the maximal tearing force is shown in Fig. 10. A clearly increasing tendency can be seen: the higher the surface roughness, the higher the tearing force and the force can be raised over $400 \mathrm{~N}$. The explanation of the increasing force tendency is the phenomenon of interlocking. By creating a bond between steel and PMMA, the soft plastic completely takes the shape of the steel pin. As it has been mentioned, the steel pieces were manufactured with turning technology. Turning has a special surface shape, there are 'valleys and peaks' on the surface, with geometrical size determined by the manufacturing settings (tool geometry, feed rate). This size is represented by the surface roughness: if the roughness is high, the valleys are deep and the peaks are high too. If the roughness is high, the plastic can fix better to the steel surface and a stronger interlocking joint can be created: the valleys are filled with molten plastic and the steel peaks are indented into the plastic. a)

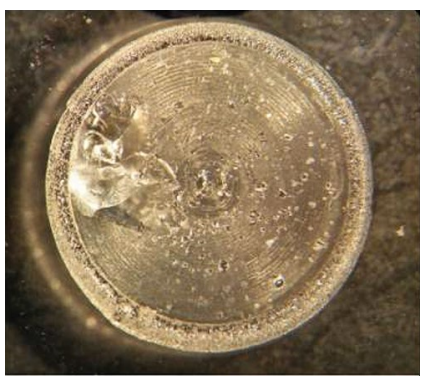

b)

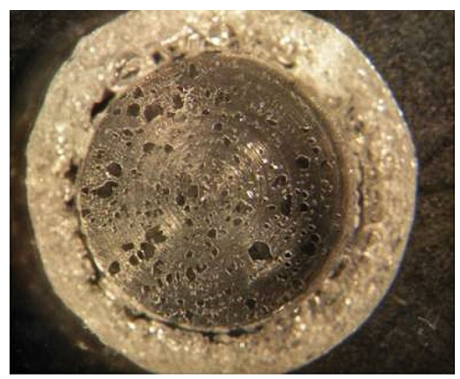

c)

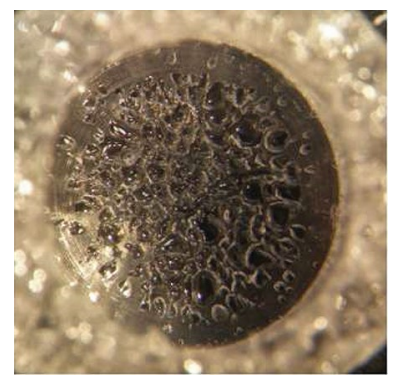

Fig. 8. Different degrees of bubble formation during the process (source: own photos): $\mathrm{a}-t_{h}=3 \mathrm{~s} ; \mathrm{b}-t_{h}=5 \mathrm{~s} ; \mathrm{c}-t_{h}=7 \mathrm{~s}$ 
a)

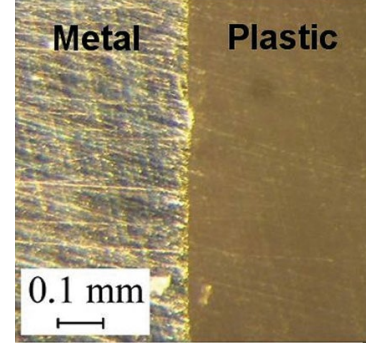

b)

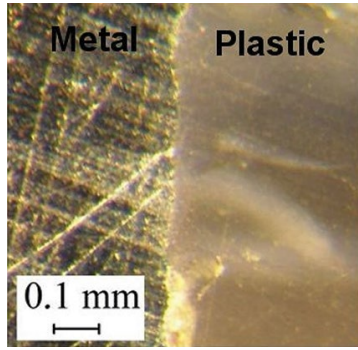

c)

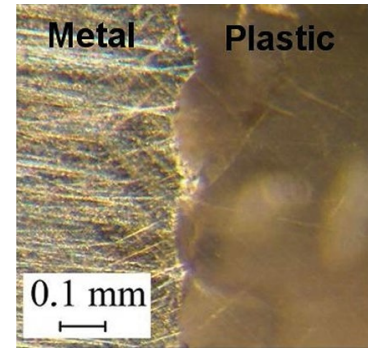

Fig. 11. Metal-plastic interfaces in case of different average surface roughness at lateral surface (source: own photos): $\mathrm{a}-R a=0.7 \mu \mathrm{m} ; \mathrm{b}-R a=6.4 \mu \mathrm{m} ; \mathrm{c}-R a=9.1 \mu \mathrm{m}$

In Fig 11. the cross sections of the joints can be seen at the cylindrical surface in case of different average surface roughness values of the metal part. The pictures show that the plastic (in the right side) can flow into the valleys of the metal surface (left side). The deeper the valleys due to roughness, the higher the shape locking effect which can enhance the maximal tearing force.

Finally, 9 samples were made to compare the results with processes using adhesives. An instant glue was used to create a bond between the steel pin and the plastic sheet: the glue was applied on the face side of the pin and the plastic was placed on the glue. The samples were torn after 2 days, the results showed that the average force is $105 \mathrm{~N}$, the deviation: $35 \mathrm{~N}$. Comparing the glued samples with the samples made by laser it can be found that the tearing force is almost always higher by the laser joined samples. The big deviation of the glued samples can be explained with the way of preparation. The samples were made by hand, and the amount of the glue applied was not always exactly the same. Nevertheless it can be seen, that with the laser technology it is possible to create similar bond strength as with gluing. Further advantage of the laser technology is that the bond is created immediately, it does not require the usage of any harmful additive materials and it is not necessary to wait after joining until the glue is hardened.

\section{Conclusions}

From this research work the following can be concluded:

- the joining of a steel pin and PMMA plastic sheet is possible by using pulse mode Nd: YAG laser without using any additive material;

- the heating time, the penetration depth and the surface roughness have an influence on the maximal tearing force;

- the longer the heating time, the deeper the penetration depth;

- the longer heating time, the deeper penetration and the higher surface roughness increase the maximal tearing force;

- to understand the high deviation present in several cases further investigations are necessary;

- it is possible to create a laser assisted hybrid metal-polymer bond which has a similar strength as those using adhesives.
It has been shown by the authors that a new technological solution had been analyzed. The new technological approach can be widely used in car industry where the plastic and metal parts are combined, but applying this new process it is necessary to know its possibilities and limits. The presented research clarified some aspects of the laser hybrid metal-plastic joining technology.

\section{Acknowledgement}

This work is connected to the scientific program of the 'Development of quality oriented and harmonized $\mathrm{R}+\mathrm{D}+\mathrm{I}$ strategy and functional model at BME' project. These projects are supported by the New Széchenyi Development Plan (Project ID: TÁMOP-4.2.1/B-09/1/ KMR-2010-0002).

\section{References}

Amanat, N.; James, N. L.; McKenzie, D. R. 2010. Welding methods for joining thermoplastic polymers for the hermetic enclosure of medical devices, Medical Engineering and Physics 32(7): 690-699.

http://dx.doi.org/10.1016/j.medengphy.2010.04.011

Devrient, M.; Frick, T.; Schmidt, M. 2011. Laser transmission welding of optical transparent thermoplastics, Physics Procedia 12A: 157-165. http://dx.doi.org/10.1016/j. phpro.2011.03.020

Horváth, E.; Harsányi, G. 2010. Optimization of fluidic microchannel manufacturing processes in low temperature cofired ceramic substrates, Periodica Polytechnica - Electrical Engineering 54(1-2): 79-86.

http://dx.doi.org/10.3311/pp.ee.2010-1-2.08

Farazila, Y.; Miyashita, Y.; Hua, W; Mutoh, Y.; Otsuka, Y. 2011. YAG laser spot welding of pet and metallic materials, Journal of Laser Micro/Nanoengineering 6(1): 69-74. http://dx.doi.org/10.2961/jlmn.2011.01.0015

Fortunato, A.; Cuccolini, G.; Ascari, A.; Orazi, L.; Campana, G.; Tani, G. 2010. Hybrid metal-plastic joining by means of laser, International Journal of Material Forming 3(1): 1131-1134.

http://dx.doi.org/10.1007/s12289-010-0971-1

Katayama, S.; Kawahito, Y. 2008. Laser direct joining of metal and plastic, Scripta Materialia 59(12): 1247-1250. http://dx.doi.org/10.1016/j.scriptamat.2008.08.026

Roesner, A.; Scheik, S.; Olowinsky, A.; Gillner, A. Reisgen, U.; Schleser, M. 2011. Laser assisted joining of plastic metal 
hybrids, Physics Procedia 12B: 370-377. http://dx.doi. org/10.1016/j.phpro.2011.03.146

Somogyi, P.; Takács, J. 2009. Laser transparent-absorbent welding of polymers, Journal of Machine Manufacturing 49(E3E5): 98-100.

Wahba, M.; Kawahito, Y.; Katayama, S. 2011. Laser direct joining of AZ91D thixomolded Mg alloy and amorphous polyethylene terephthalate, Journal of Materials Processing Technology 211(6): 1166-1174.

http://dx.doi.org/10.1016/j.jmatprotec.2011.01.021

Wang, X.; Li, P.; Xu, Z.; Song, X.; Liu, H. 2010. Laser transmission joint between PET and titanium for biomedical application, Journal of Materials Processing Technology 2010(13): 1767-1771.

http://dx.doi.org/10.1016/j.jmatprotec.2010.06.007 